\title{
Towards High Level of Presence: Combining Static Infrastructure with Dynamic Services
}

\author{
Hao Liu,Cheefai Tan,Jun Hu,Matthias Rauterberg \\ Industrial Design Department \\ Technische Universiteit Eindhoven \\ Eindhoven, Netherlands \\ \{hao.liu, c.f.tan, j.hu, g.w.m.rauterberg \}@tue.nl
}

\begin{abstract}
In this paper, we present a new approach to facilitate test subjects to achieve a high level of presence in a long haul flight simulator. The approach not only addresses the likeness of the static infrastructure, but also highlights the importance of integrating the dynamic services, such as flight attendant service, flying simulation service, etc. with the static infrastructure to create a dynamic flight virtual environment for test subjects. The integration procedure is a time driven unified process. User experiment result shows that the approach helps test subjects to achieve a high level of flight presence in the flight simulator.
\end{abstract}

Keywords-long-haul flight simulation, presence, test bed, simulator.

\section{INTRODUCTION}

SEAT (smart tEchnologies for Stress free Air Travel) is a European sixth framework project [1]. It aims to develop adaptive cabin systems to enable stress free air travels. In order to validate the design concept of adaptive systems, a long-haul flight simulator is built in the technical university of Eindhoven. However, giving test subjects a high level of long haul flight presence is the precondition of the success of the flight simulator. Presence is defined as the subjective experience of being in one place or environment, even when one is physically situated in another [2]. In this paper's context, presence means the "passenger's" subjective experience of being in the long haul flight; even when the "passenger's" is physically sit in a flight simulator built in a Lab.

In this paper, we present a new approach to help test subjects to achieve a high level of long haul flight presence in a flight simulator. The approach not only addresses the importance of the cabin like physical environment, but also highlights integrating dynamic services such as flight attendant service, flying simulation service, etc. with the static infrastructure to create a dynamic flight virtual environment to test subjects. The integration procedure is a time driven unified process.

The rest of this paper is organized as follows. Firstly, the SEAT test bed is introduced in section 2. Then the new approach is presented in section 3. Following that, the method of the flight simulator presence measurement is given in section 4 . After that, the user experiment to validate the effectiveness of the new approach is introduced in section 5. Finally, Conclusions are drawn in Section 6.

\section{SEAT TEST BED}

The SEAT simulator consists of a small scale aircraft cabin residing on a moving platform, a project section to simulate the aircraft cabin outside sky, and a control room section. The interior of the aircraft cabin is divided into an economy class section, a business class section, a galley and a lavatory. The projection section include a beamer hangs above the aircraft cabin and a projection wall next to the aircraft cabin. The control room is equipped with the state of art of computers to support in-seat computers in the aircraft cabin and long haul flight simulation.

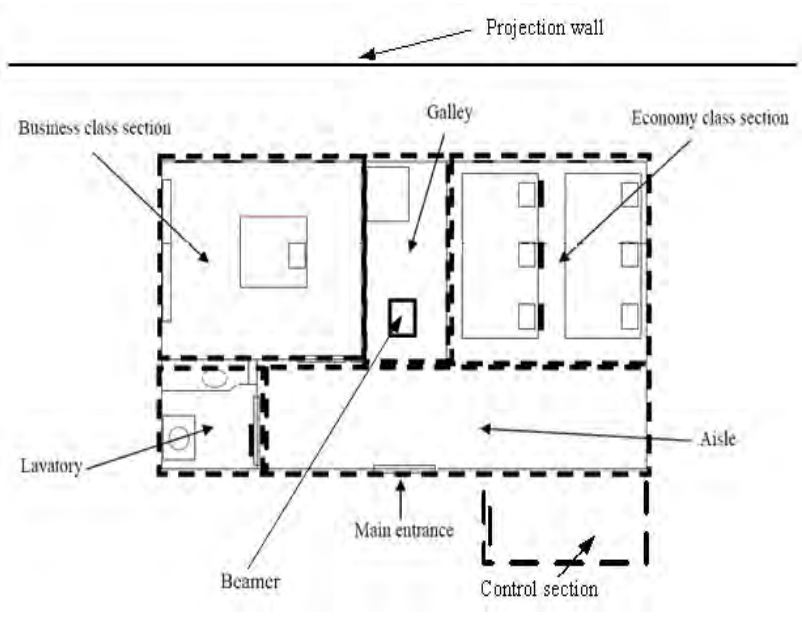

Figure 1. Test bed overview

The business class section equips with a massage chair, a touch screen monitor, a high quality surround sound system and a 47 inches ambient LCD television. There are six economic class seats in the economic class section. Each seat is equipped with a private entertainment touch screen monitor and a noise cancelling ear phone by which the passenger can enjoy on-demand entertainment (refer to figure 2 and 3). Under the luggage compartment, there is a broadcasting system, an air ventilation system, and a lighting system. Figure 2 is a snapshot of the economy class section. The aircraft cabin in the test bed is also designed with a galley and a lavatory to enable long haul flight simulations. The galley is equipped with a refrigerator, a microwave and a peripheral compartment. The galley is used to provide the 
H. Liu, C. Tan, J. Hu, and M. Rauterberg, "Towards high level of presence: Combining static infrastructure with dynamic services," in 2010 International Conference On Electronics and Information Engineering (ICEIE), Kyoto, Japan, 2010, pp. V2-535-V2-539.

food and beverage to the passenger. The lavatory is equipped with a portable toilet, a wash basin.

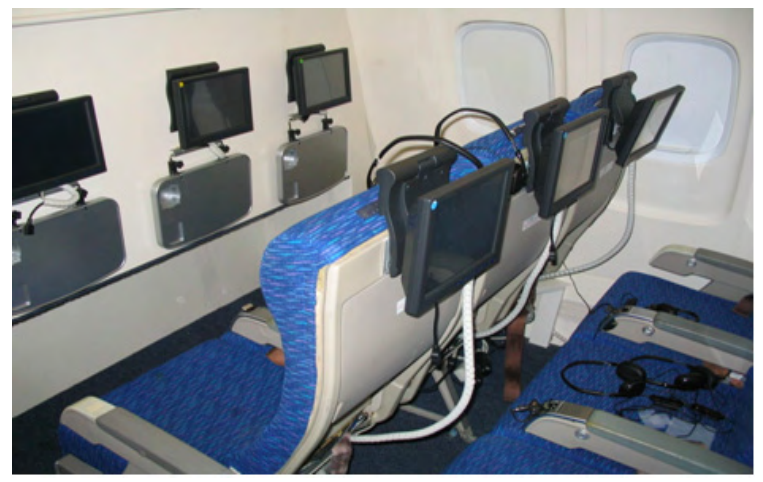

Figure 2. Economic class section
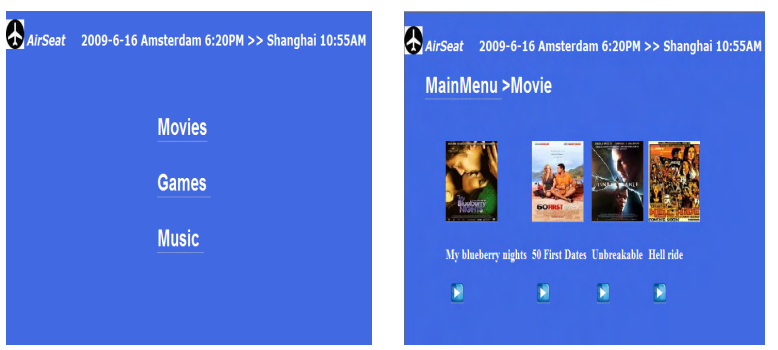

Figure 3. In-flight entertainment

The projection section consists of a projection screen (a semi circle wall and its neighboring floor that are painted in white color) and one wide screen LCD beamer. It is used to simulate outside sky from the aircraft cabin window point of view.

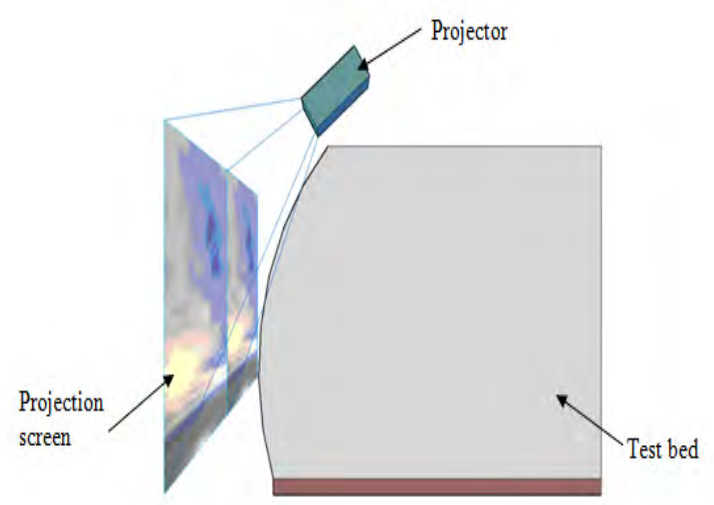

Figure 4. Projection

The moving platform is composed by a control computer, compressed air and four air bags. Each air bag supports one corner of the aircraft cabin. The computer controls air bags to flate/deflate to up/down lift the aircraft cabin to simulate the take off, landing, turbulence, flying situations, etc.
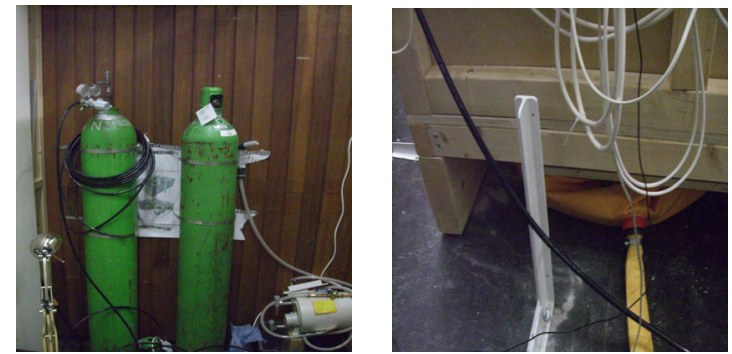

Figure 5. Compressed air and air bags

The control room is equipped with the state of art computer systems which are used to control and monitor the simulator. There are three categories of computers in the control room: category I computer is composed by six desktop PCs. Each PC support one in-seat touch screen to provide in-flight entertainment to flight passengers and one monitor in the control room to configure and observe the passenger's entertainment behaviors. Category II computer consists of one desktop PC to support the observing system in the economic class. The observation system helps the experiment staff to be aware of what is going on in the aircraft cabin during the long haul flight experiments. Category III computer is composed by two desktop PCs. One is used to support the sky view projection. The other is used to simulate flying situations.

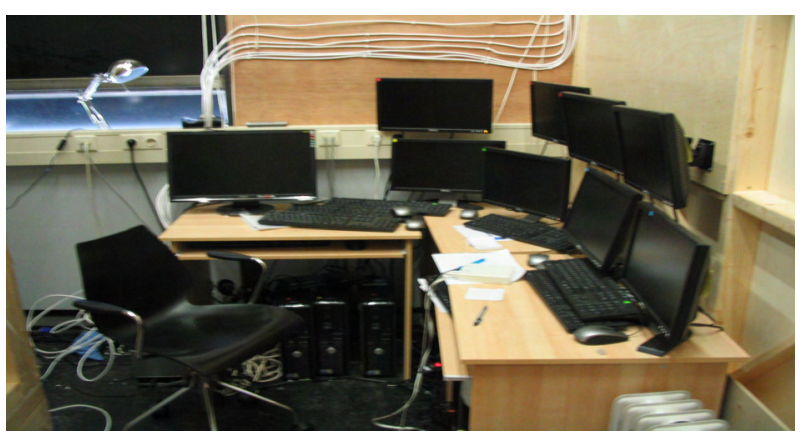

Figure 6. Control room

\section{THE NEW APPROACH}

In this section, we first introduce the dynamic services provided to the subjects during the long haul flight simulation, then the time-driven unified process to integrate dynamic services with the static infrastructures is presented.

\section{A. Dynamic services}

\section{(1) Flight attendant service}

The role of a professional flight attendant during the user experiment has three folds: (1) customer service which is part of ensuring "passengers" having a pleasant journey; (2) ensure the safety and security of the experiment. Security regulations are followed as well as being capable of administering unexpected accident aids to enable user 
experiments going smoothly; (3) Giving the test subjects the real flight perception.

\section{(2) Captain information service}

Captain information service includes ssafety instruction, turbulence alert, and etc message broadcasting. It is important for the test subject aware of the flight situations.

\section{(3) Window view projection service}

To simulate real time airport and sky views of long haul flights from an aircraft window perspective, time and flying stage awareness is necessary. A local time and flying stage aware video has been edited for the test bed projection. Its time-aware views include dawn, dusk, dark, day, etc. (figure 7) and its flying stage-aware views include different flying stages. Flying time and stage are synchronized with each other. The local time is computed by the equation 1 where $T_{\text {depart }}$ is the local time of the flight depart city, $t_{\text {flying }}$ is the flight's relative flying hours, $T_{\text {arrival }}$ is the local time of the flight arrival city. The flying stages include boarding, taxing, take off, flying, landing, taxing and unboarding (refer to figure 8).

$$
T_{\text {local }}=T_{\text {depart }}+\frac{t_{\text {flying }}}{T_{\text {arrival }}-T_{\text {depart }}} \text { (Equation1) }
$$
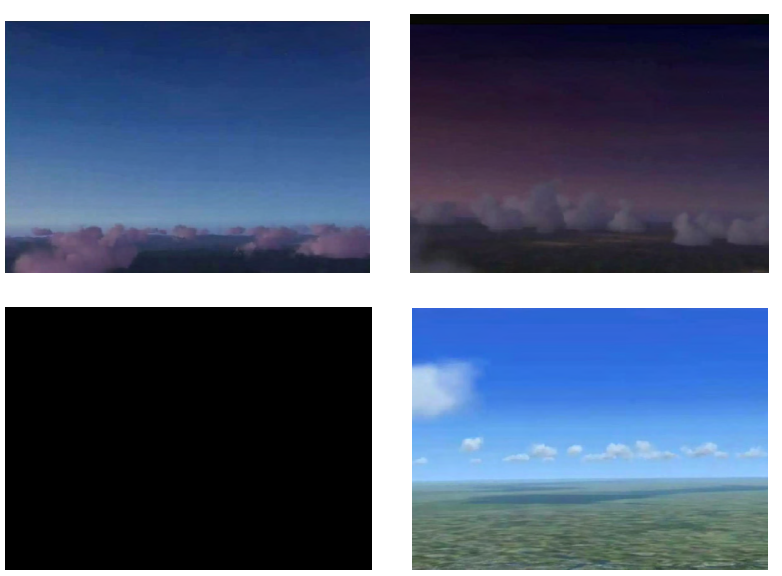

Figure 7. Dawn,duskm night and day window view

(4) Moving platform service

By controlling air bags to flate/deflate, the aircraft cabin can be uplifted/down lifted to simulate the take off, landing, turbulence, flying, etc. flying situations.
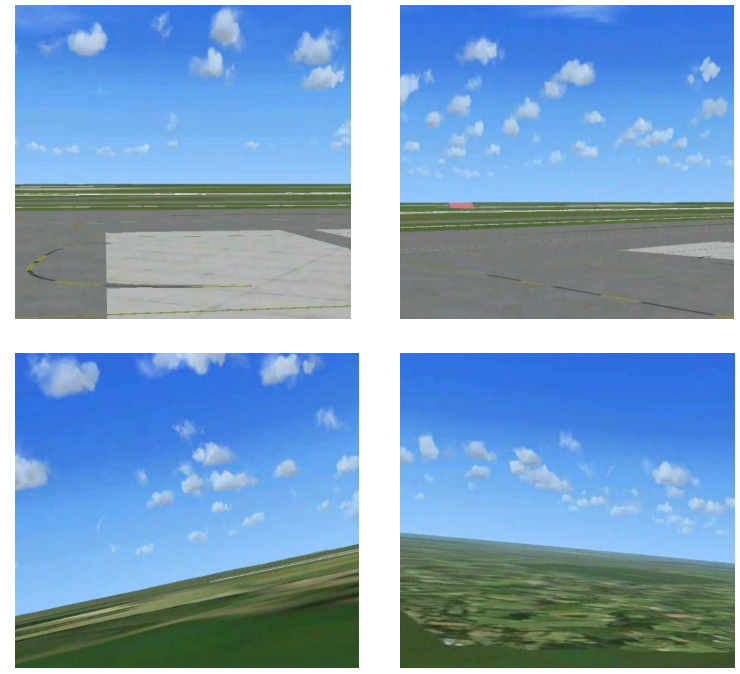

Figure 8 . boarding, taxing, take off and landing window view

\section{B. The unified process}

The unified process integrates the static infrastructures introduce in section 2 with the dynamic services introduced in section 3 to create a dynamic virtual environment to give test subjects long haul flight experiences. The process is a time-driven workflow. The boarding, taxing, take off, flying, turbulences, landing, unboarding flying situations are simulated by the synchronization of moving platform service and window view projection service, and are enhanced by the captain information service and flight attendant service. Figure 9 gives an instance of the unified process. The process can be implemented with the work flow technology.

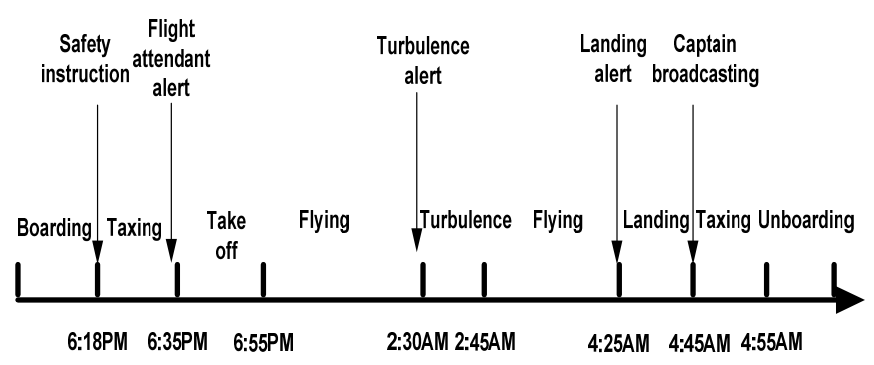

Figure 9. Time-driven unnified process

\section{PRESENCE}

A common measure of the effectiveness of a simulator is the amount of presence it evokes in users. Presence is commonly defined as the sense of being there in a virtual environment. In order to study the effectiveness of the approach introduced in section 3, we must be able to measure it. The presence questionnaire in [2] is used to measure the user presence. We have customized it to our test bed with the following five questions: 
H. Liu, C. Tan, J. Hu, and M. Rauterberg, "Towards high level of presence: Combining static infrastructure with dynamic services," in 2010 International Conference On Electronics and Information Engineering (ICEIE), Kyoto, Japan, 2010, pp. V2-535-V2-539.

2010 International Conference on Electronics and Information Engineering (ICEIE 2010)

1. Please rate your sense of being in the long haul flight on the following scale from 1 to 7 .

I had a sense of "being there" in the long haul flight:

$$
\begin{array}{lllllllll}
\text { Not at all } & \bigcirc & \bigcirc & 0 & \bigcirc & \bigcirc & \bigcirc & \bigcirc & \text { Very much }
\end{array}
$$

2. To what extent were there times during the experience when the laboratory became the "real long haul flight" for you, and you almost forgot about the "real world" of the laboratory in which the whole experience was really taking place?

There were times during the experience when the virtual "long haul flight" became more real for me compared to the "real flight"...

$\begin{array}{ccccccccc}\text { At no time } & \bigcirc & \bigcirc & \bigcirc & \bigcirc & \bigcirc & \bigcirc & \bigcirc & \begin{array}{c}\text { Almost all } \\ \text { the time }\end{array} \\ 1 & 2 & 3 & 4 & 5 & 6 & 7 & \end{array}$

3. When you think back about your experience, do you think of the laboratory more as the lab that you saw, or more as somewhere that you visited? Please answer on the following 1 to 7 scale:

The laboratory seems to me to be more like...

$\begin{array}{ccccccccc}\begin{array}{c}\text { Laboratory that } \\ \text { I saw }\end{array} & \bigcirc & \bigcirc & \bigcirc & \bigcirc & \bigcirc & \bigcirc & \bigcirc & \begin{array}{c}\text { somewhere } \\ \text { that I visited }\end{array} \\ & 1 & 2 & 3 & 4 & 5 & 6 & 7 & \end{array}$

4. During the time of the experience, which was the strongest on the whole, your sense of being in the long haul flight, or of being in the real world of the laboratory?

I had a stronger sense of being in...

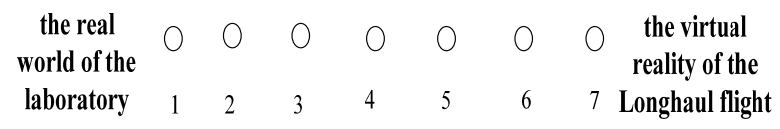

5. During the time of the experience, did you often think to yourself that you were actually just sitting in a laboratory or did the "long haul flight" overwhelm you?

During the experience I often thought that I was really sitting in the laboratory....

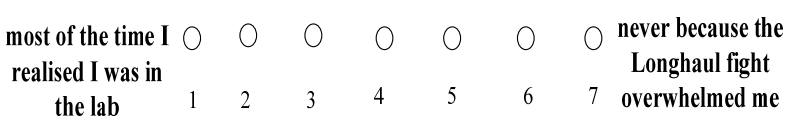

\section{USER EXPERIMENT}

User experiments to validate the adaptive music framework for stress free air travels [3] [4] [5] [6] [7] [8] have been done in the test bed. Twelve subjects were invited to participate in user experiments. Six were allocated to the controlled group and others were allocated to the treatment group. The ages of the control group range from 21 to 33 . The ages of the treatment group range from 23-32. The professions in the control group include one reporter, two workers and three engineers. The professions in the treatment group include one student, two workers and three engineers. KLM KL0895 flight from Amsterdam Schipol international airport $(6: 20 \mathrm{PM})$ to Shanghai Pudong international airport (10:45 $\mathrm{AM}<$ Shanghai time $>$, 4:55AM $<$ Amsterdam time $>$ ) is simulated in the test bed on $31 \mathrm{st}$ (Friday), July 2009 (the controlled group user experiment) and 7th (Friday), August 2009 (the treatment group user experiment). A professional flight attendant from Swiss Air was invited to act as the flight attendant during the experiments (figure 10). Flight attendant service, captain information service, moving platform service and projection service are coordinated in accordance with the unified process in figure 9. The presence questionnaires are distributed to the subjects right after the test.

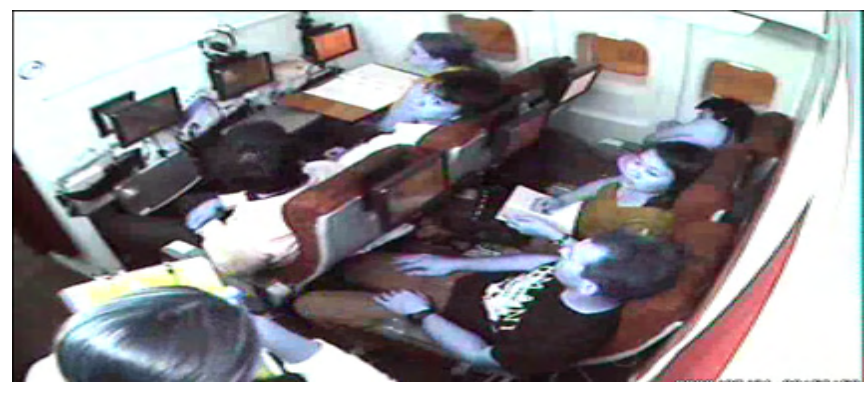

Figure 10. User experiment

Table I presents the result based on the twelve test subjects' answers. All the five questions scored above 3.5, which is quite an achievement for our flight simulator.

TABLE I. SUBJECTS' PRESENCE

\begin{tabular}{|c|r|r|r|}
\hline & $\mathrm{N}$ & Mean & Std. Deviation \\
\hline BeingThere & 12 & 4,0000 &, 73855 \\
RealFlight & 12 & 3,7500 & 1,21543 \\
LaboratoryOrSomewhere & 12 & 3,5833 &, 79296 \\
LaboratoryFlight & 12 & 3,9167 &, 79296 \\
SitLabOrFlight & 12 & 3,5000 & 1,08711 \\
Valid N (listwise) & 12 & & \\
\hline
\end{tabular}


H. Liu, C. Tan, J. Hu, and M. Rauterberg, "Towards high level of presence: Combining static infrastructure with dynamic services," in 2010 International Conference On Electronics and Information Engineering (ICEIE), Kyoto, Japan, 2010, pp. V2-535-V2-539.

2010 International Conference on Electronics and Information Engineering (ICEIE 2010)

\section{CONCLUSIONS}

Enabling the test subjects to achieve a high level of presence is the precondition of any success simulators. However, it is not easy because it needs not only the highly likeness physical environment but also a highly likeness virtual environment. In this paper, we present a new approach to help the test subjects to achieve a high level of long haul flight presence in the flight simulator. The approach not only addresses the importance of the cabin like physical environment, but also the static infrastructure is integrated with the dynamic services by a unified process. User experiments show that our approach enables the test subjects to achieve a high level of flight presence in our test bed.

\section{ACKNOWLEDGMENT}

This project is sponsored by the European Commission DG H.3 Research, Aeronautics Unit under the 6th Framework Programme, under contract Number: AST5-CT2006-030958.

\section{REFERENCES}

[1] SEAT project, www.seat.id.tue.nl.

[2] Bob G. Witmer Michael J. Singer: "Measuring Presence in Virtual Environments: A Presence Questionnaire", Presence, Vol. 7, No. 3 , June 1998, 225-240.
[3] H. Liu, J. Hu, and G. W. M. Rauterberg, "AIRSF: A New Entertainment Adaptive Framework for Stress Free Air Travels ”, in Proceedings of the International Conference on Advances in Computer Entertainment Technology (pp. 183-186), 2008, ACM Press.

[4] H. Liu, J. Hu, and G. W. M. Rauterberg, "Adaptive User Preference Modeling and Its Application to In-flight Entertainment", in Proceedings of 3rd International Conference on DigitalInteractive Media in Entertainment and Arts, 2008, ACM ISBN: 978-1-60558248-1, pp. 289-294.

[5] H. Liu, M. Rauterberg, "Context-aware in-flight entertainment system", in Proceedings of Posters at 2007 HCI International: Part X (LNCS CD-Rom [ISBN 978-3-540-73332-4], pp. 1249-1254), 2007 , Springer.

[6] H. Liu, J. Hu, and G. W. M. Rauterberg, "Music Playlist Recommendation Based on User Heartbeat and Music Preference," in Proceedings of 2nd IEEE 2009 International Conference on Computer Technology and Development(ICCTD '09), 2009, pp. 545-549.

[7] H. Liu, J. Hu, and G. W. M. Rauterberg, "Bio-feedback Based Inflight Music System Design to Promote Heart Health," in Proceedings of 2009 International Conference on Machine Learning, 2009, pp. 446-450.

[8] H. Liu, J. Hu, and M. Rauterberg, "Software Architecture Support for Biofeedback Based In-flight Music Systems," in 2nd IEEE International Conference on Computer Science and Information Technology (ICCSIT 2009), Beijing, China, 2009, pp. 580-584. 